\title{
CARACTERIZAÇÃO DA SILAGEM DE SORGO PRODUZIDA NO SUDOESTE DO PARANÁ-PR, BRASIL
}

\author{
Thomas Newton Martin ${ }^{1}$, Sonia Santos ${ }^{2}$, Patricia Bertoncelli ${ }^{1}$, Francisdo Antônio Piran Filho ${ }^{3}$, \\ Vinícius dos Santos Cunha ${ }^{1}$, Diógenes Barella Pahins ${ }^{1}$ \\ ${ }^{1}$ Universidade Federal de Santa Maria (UFSM), Santa Maria, RS, E-mail: martin.ufsm@gmail.com, \\ patybertoncelli@hotmail.com, vinicius_scunha@hotmail.com,dbarella66@hotmail.com \\ ${ }^{2}$ Universidade Tecnológica Federal do Paraná, Dois Vizinhos, PR, E-mail: soninhax_@hotmail.com \\ ${ }^{3}$ Universidade Tecnológica Federal do Paraná, Campus Dois Vizinhos, E-mail: chicofapf@gmail.com
}

\section{RESUMO}

Este trabalho teve como objetivo avaliar e caracterizar o sistema produtivo da cultura do sorgo para ensilagem, bem como, verificar a utilização em propriedades leiteiras da região Sudoeste do Paraná. A coleta dos dados foi realizada durante os anos de 2009 e 2010, sendo baseada em questionário aplicado a 101 propriedades que possuem atividade leiteira e utilizam a silagem de sorgo na nutrição do seu rebanho. O questionário possuía questões referentes às características das propriedades e manejos aplicados na cultura. A região Sudoeste do Paraná é representada por pequenas propriedades, voltadas para agricultura familiar. O desenvolvimento e a produtividade da cultura do sorgo são afetados principalmente pelas técnicas de manejo, que em certos casos ainda tem sua importância desconhecida pelos produtores.

Palavras-chave: Agricultura familiar, atividade leiteira, manejo, Sorghum bicolor

\section{CHARACTERIZATION OF SORGHUM SILAGE PRODUCED IN THE SOUTHWESTERN REGION OF PARANA STATE, BRAZIL}

\begin{abstract}
This paper evaluates and characterizes the production system of sorghum for silage, as well as verifies its use in dairy farms in the Southwestern region of Paraná State, Brazil. Data collection was performed during the years 2009 and 2010, being based on a questionnaire sent to 101 properties that have the dairy business and use the sorghum silage in the nutrition of their herd. The questionnaire had questions regarding the characteristics of properties and management systems applied to the crop. The Southwestern region of Paraná is represented mostly by small farms, household production. The development and productivity of sorghum are affected mainly by management techniques, which, in some cases, still have their importance unknown by producers.
\end{abstract}

Keywords: Family farming, milk activity, management, Sorghum bicolor

\section{INTRODUÇÃO}

A região Sudoeste do Paraná é
composta basicamente por pequenas
propriedades rurais, voltadas para agricultura
familiar, onde a atividade agropecuária é
diversificada. Dentre as atividades
realizadas, destaca-se a bovinocultura
leiteira, que vem obtendo expressivo
crescimento na região, passando a

desempenhar importante papel na melhoria da qualidade de vida e poder econômico das famílias.

De acordo com dados do Instituto Paranaense de Desenvolvimento Econômico e Social - IPARDES, no ano de 2010, o Estado do Paraná produziu 3,5 bilhões de litros de leite, sendo a região Sudoeste do Paraná responsável por aproximadamente 
956 milhões de litros de leite (IPARDES, 2010). Dessa forma, essa região é uma das principais bacias leiteiras do Brasil. Apesar da produção ser expressiva, ainda existe possibilidade de expansão da produção pelo aumento da produtividade média dos animais.

Diversos são os fatores que poderão influenciar os índices zootécnicos relacionados à produção e reprodução do rebanho, dentre eles destaca-se o ambiente, a genética (PAULA et al., 2009), o manejo higiênico-sanitário (GUERREIRO et al., 2005) e a nutrição animal (MOREIRA et al., 2001). Dentre esses fatores, a nutrição pode ser responsável por até $70 \%$ do custo total de produção, possuindo assim importância destacada.

Uma das maiores dificuldades da produção de leite no Sul do Brasil está relacionada à nutrição do rebanho, devido à escassez de alimentos, principalmente no período compreendido entre os meses de abril/maio e setembro/outubro, período esse conhecido como vazio forrageiro (OLIVEIRA et al., 2004). Nesses períodos, a quantidade e a qualidade das pastagens diminuem acentuadamente, reduzindo ou inviabilizando a produção de leite em escala comercial. Para amenizar as possíveis perdas e alcançar maior equilíbrio no sistema, podese realizar a conservação de forragens. Dentre as técnicas empregadas destaca-se a ensilagem, a qual é realizada em épocas de abundância, sendo seu produto armazenado para ser utilizado nos períodos de escassez de alimento.

A cultura do sorgo (Sorghum bicolor (L.) Moench), dentre tantas outras com potencial para ensilagem, tem sido uma espécie bastante utilizada pelo alto valor nutritivo (MELLO et al., 2003), elevado rendimento de grãos e produção de matéria seca, boa digestibilidade de fibras (NEUMANN et al., 2005), maior resistência ao estresse hídrico (AMARAL et al., 2003), além da qualidade do produto final, o qual garante suprir as necessidades alimentares do rebanho em períodos de baixa disponibilidade de volumoso.

A contribuição da silagem de sorgo na produção de leite está diretamente relacionada com a qualidade do material fornecido aos animais (DIAS et al., 2001), logo se tem como objetivo principal da ensilagem, manter o teor de matéria seca colhida e promover o mínimo possível de perdas dos nutrientes. Dessa forma, a qualidade do produto final irá depender de fatores como a escolha da cultivar (SILVA et al., 2007), implantação da cultura e sistema de plantio (NEUMANN et al., 2008), manejo de ensilagem e descarregamento, tratamento de sementes (VANIN et al., 2011), controle de pragas, doenças e plantas daninhas na lavoura, dentre outros.

Sendo assim, é de suma importância que o produtor tenha conhecimento dos valores referentes à composição da silagem, para saber a qualidade do produto que está fornecendo ao seu rebanho. Valores estes, obtidos por meio de análises químicobromatológicas, que auxiliam na formulação de uma dieta balanceada, melhorando a produtividade, reduzindo custos e consequentemente melhorando a renda dos produtores.

O entendimento da relação entre os fatores de produção e os sistemas produtivos, permite identificar deficiências no sistema, conseguindo-se então direcionar o manejo de acordo com a realidade e necessidades da propriedade. Assim, acaba promovendo a otimização do sistema produtivo como um todo, garantindo melhor rentabilidade da atividade.

Dessa forma, objetivou-se com esse trabalho avaliar e caracterizar o sistema produtivo da cultura do sorgo para ensilagem, bem como verificar sua utilização em propriedades leiteiras localizadas na região Sudoeste do Paraná, para posteriormente subsidiar programas de 
Pesquisa e Desenvolvimento, além da transferência de tecnologias aos produtores da região.

\section{MATERIAL E MÉTODOS}

O trabalho foi baseado em questionários aplicados a produtores de sorgo da região Sudoeste do Paraná, por dois anos consecutivos, 2009 e 2010, durante o período de setembro a dezembro de cada ano. Foram escolhidas, aleatoriamente, propriedades rurais produtoras de leite que utilizam na alimentação do rebanho a silagem de sorgo. As propriedades entrevistadas nos diferentes anos não foram as mesmas, de forma a totalizar 101 propriedades diferentes, sendo 50 produtores entrevistados no ano de 2009 e 51 produtores em 2010.

Participaram do estudo os seguintes municípios e número de produtores entrevistados, em cada ano, respectivamente: Bom Sucesso do Sul (1 em 2009; 5 em 2010), Capanema (10 em 2010), Catanduvas (3 em 2010), Chopinzinho (6 em 2009; 1 em 2010), Cruzeiro do Iguaçu (5 em 2009; e 3 em 2010), Dois Vizinhos (12 em 2009; 6 em 2010), Francisco Beltrão (1 em 2009), Itapejara D'Oeste (3 em 2009), Nova Laranjeiras (2 em 2010), Nova Prata do Iguaçu (2 em 2009; 2 em 2010), Planalto (1 em 2009; 1 em 2010), Pranchita (1 em 2010), Realeza (1 em 2010), Salto do Lontra (1 em 2009; 2 em 2010), Santa Izabel do Oeste (7 em 2010), Santo Antônio do Sudoeste (1 em 2009), São João (3 em 2009), São Jorge D'Oeste (13 em 2009; 3 em 2010) e Verê (1 em 2009; 4 em 2010).

O clima da região Sudoeste do Paraná é classificado como Cfa (Clima subtropical Úmido - Mesotérmico), com média do mês mais quente superior a $22^{\circ} \mathrm{C}$ e do mês mais frio inferior a $18^{\circ} \mathrm{C}$, sem estação seca definida, verão quente e geadas menos frequentes (MAARK, 1968).
No questionário foram abordados tópicos referentes a área total da propriedade, área cultivada para a ensilagem por ano, origem das sementes, ciclo da cultivar, espaçamento entre fileiras, adubação nitrogenada, tratamento de sementes, sistema de semeadura, cultura antecessora, controle de plantas daninhas, controle de pragas, principal praga, mão de obra utilizada para realizar ensilagem, relação de propriedade da ensiladeira, afiação de facas e contra-facas no dia da ensilagem, tipo de silo, forma de compactação da ensilagem, local onde ocorrem as maiores perdas de silagem, análise químico-bromatológica da silagem, tamanho estimado do silo, produção média estimada de silagem por hectare, período de uso da silagem, composição do rebanho, raças dos bovinos leiteiros, produção média de leite por vaca/dia.

Utilizou-se o software Excel@ para tabular as respostas dos questionários e, assim, formar o banco de dados. A partir desse, cada pergunta foi tratada de forma única, realizando-se então agrupamento por classes e estimando-se as estatísticas de posição (média, mínima e máxima) e de dispersão (desvio padrão, variância e coeficiente de variação).

\section{RESULTADOS E DISCUSSÃO}

A área total média das propriedades analisadas durante os anos de 2009 e 2010 foi de 26,51 ha e 33,94 ha respectivamente, variando de 5 ha a 200 ha (Tabela 1). As áreas utilizadas para o cultivo de sorgo para ensilagem oscilaram de 1 a 60 ha, com média de 3,44 ha cultivados no ano de 2009 e de 7,48 ha para o ano seguinte. A produção de silagem média estimada em matéria verde de 43,25 t/ha em 2009 e de 36,18 t/ha em 2010, resultados esses semelhantes aos encontrados por Neumann et al. (2002), que obtiveram variações de produção de matéria verde de 22,70 a 39,56 t/ha. 
Tabela 1. Estatística descritiva para as variáveis de área total da propriedade (AT, ha), área cultivada com sorgo para silagem (AC, ha), espaçamento entre linhas (EL, cm), tamanho do silo (TS, $\mathrm{m}^{-3}$ ), produção de silagem (PSI, $\mathrm{t} \mathrm{ha}^{-1}$ ), produção de leite por vaca por dia (PL, Litros).

\begin{tabular}{|c|c|c|c|c|c|c|}
\hline \multicolumn{7}{|c|}{2009} \\
\hline Estatísticas & AT & $\overline{A C}$ & EL & TS & PSI & $\overline{\mathbf{P L}}$ \\
\hline Média & 26,51 & 3,44 & 0,70 & 140,65 & 43,25 & 16,74 \\
\hline Mínimo & 6,00 & 1,00 & 0,45 & 18,00 & 10,00 & 9,00 \\
\hline Máximo & 123,50 & 8,50 & 0,90 & 600,00 & 70,00 & 30,00 \\
\hline Mediana & 22,65 & 3,00 & 0,75 & 105,00 & 42,50 & 16,00 \\
\hline EP & 0,44 & 0,03 & 0,00 & 1,85 & 0,48 & 0,11 \\
\hline DP & 22,06 & 1,77 & 0,15 & 106,66 & 15,45 & 5,40 \\
\hline Curtose & 8,86 & 0,38 & $-0,96$ & 8,70 & $-0,43$ & 0,24 \\
\hline Assimetria & 0,21 & $-2,64$ & $-1,99$ & 1,42 & 0,63 & 2,63 \\
\hline $\mathbf{C V}$ & 83,22 & 51,55 & 21,68 & 75,83 & 35,71 & 32,26 \\
\hline \multicolumn{7}{|c|}{2010} \\
\hline Estatísticas & AT & $\overline{\mathrm{AC}}$ & EL & TS & PSI & $\mathbf{P L}$ \\
\hline Média & 33,94 & 7,48 & 0,55 & 141,42 & 36,18 & 14,59 \\
\hline Mínimo & 5,00 & 1,00 & 0,30 & 24,00 & 22,00 & 5,00 \\
\hline Máximo & 200,00 & 60,00 & 0,90 & 750,00 & 50,00 & 30,00 \\
\hline Mediana & 22,00 & 3,00 & 0,45 & 60,00 & 35,00 & 14,50 \\
\hline EP & 0,70 & 0,23 & 0,00 & 3,66 & 0,30 & 1,22 \\
\hline DP & 35,78 & 11,79 & 0,15 & 164,85 & 8,23 & 5,88 \\
\hline Curtose & 8,60 & 9,60 & $-0,13$ & 4,20 & $-1,01$ & 0,35 \\
\hline Assimetria & 1,83 & 1,39 & 2,04 & $-0,72$ & $-1,39$ & $-0,20$ \\
\hline $\mathbf{C V}$ & 105,42 & 157,53 & 28,42 & 116,57 & 22,75 & 40,30 \\
\hline \multicolumn{7}{|c|}{ Média dos dois anos } \\
\hline Estatísticas & $\mathbf{A T}$ & $\overline{\mathrm{AC}}$ & EL & TS & PSI & $\mathbf{P L}$ \\
\hline Média & 30,26 & 5,48 & 0,63 & 141,06 & 40,02 & 15,69 \\
\hline Mínimo & 5,00 & 1,00 & 0,30 & 18,00 & 10,00 & 5,00 \\
\hline Máximo & 200,00 & 60,00 & 0,90 & 750,00 & 70,00 & 30,00 \\
\hline Mediana & 22,00 & 3,00 & 0,60 & 90,00 & 40,00 & 15,00 \\
\hline EP & 0,30 & 0,09 & 0,00 & 1,64 & 0,22 & 0,06 \\
\hline DP & 22,06 & 8,68 & 0,17 & 139,71 & 13,06 & 5,71 \\
\hline Curtose & 10,94 & 21,50 & $-1,45$ & 5,70 & $-0,03$ & 0,21 \\
\hline Assimetria & 0,53 & 1,20 & 3,13 & 2,17 & 0,00 & 1,94 \\
\hline $\mathrm{CV}$ & 98,73 & 158,22 & 27,08 & 99,04 & 32,63 & 36,42 \\
\hline
\end{tabular}

Notou-se que a importância da escolha do ciclo da cultivar ainda não está clara para os produtores, devido a grande variabilidade que ocorreu de um ano para outro (Tabela 2). Além do resultado obtido em 2010, em que 52\% dos produtores não 
souberam responder qual era o ciclo da cultivar utilizada. Logo, nota-se a necessidade de adoção de políticas públicas ou então programas de extensão rural que promovam a disseminação de informações e tecnologias aos produtores rurais.

De acordo com os resultados verificados, percebe-se que os produtores estão cada vez mais optando por utilizar sementes certificadas (Tabela 3). Estas sementes são produzidas dentro de um sistema com tecnologias adequadas, testadas e comprovadas geneticamente quanto à sua qualidade e desempenho produtivo. Segundo dados da Associação Paulista dos Produtores de Sementes e Mudas (CARRARO, 2009), a utilização de sementes de sorgo certificadas no Brasil chega a $67 \%$, sendo que na região Sudoeste do Paraná, mais de $75 \%$ dos produtores, em ambos os anos de realização do estudo, adquiriram sementes certificadas em agropecuária.

Tabela 2. Ciclo das cultivares de sorgo para produção de silagem utilizados em 2009 e 2010, com o respectivo número de produtores (NP) e a representatividade em porcentagem $(\%)$.

\begin{tabular}{lcccc}
\hline & \multicolumn{2}{c}{$\mathbf{2 0 0 9}$} & \multicolumn{2}{c}{$\mathbf{2 0 1 0}$} \\
\hline Ciclo & NP & $\mathbf{( \% )}$ & NP & $\mathbf{( \% )}$ \\
\hline Hiperprecoce & 0 & 0 & 1 & 2 \\
Superprecoce & 4 & 8 & 8 & 16 \\
Precoce & 12 & 24 & 9 & 18 \\
Normal & 26 & 52 & 6 & 12 \\
Não sabem & 8 & 16 & 26 & 52 \\
\hline Total & 50 & 100 & 50 & 100 \\
\hline
\end{tabular}

Tabela 3. Origem das sementes de sorgo utilizadas em 2009 e 2010, com o respectivo número de produtores (NP) e a representatividade em porcentagem (\%).

2009

2010

\begin{tabular}{lcccc}
\hline Origem de sementes & NP & $\mathbf{( \% )}$ & NP & $\mathbf{( \% )}$ \\
\hline Própria & 3 & 6 & 11 & 21,56 \\
Agropecuária certificada & 38 & 76 & 39 & 76,47 \\
Ganhou & 9 & 18 & 1 & 1,97 \\
\hline Total de Produtores & 50 & 100 & 51 & 100,00 \\
\hline
\end{tabular}


Dentre os produtores entrevistados, $74 \%$ no ano de 2009 e 80,39\% em 2010, realizaram o tratamento de sementes, o qual serve como ferramenta auxiliar no controle de pragas na lavoura. Porém, apenas o tratamento de sementes não assegura a lavoura totalmente contra a incidência de pragas, doenças ou plantas daninhas, sendo necessário que seja realizado o monitoramento constante da lavoura, para garantir a produtividade.

Dessa forma, $74 \%$ dos produtores entrevistados em 2009 e 86,27\% em 2010, realizam o controle de plantas daninhas em suas lavouras de sorgo. Já no que se refere ao controle de pragas, o número de produtores que aplicaram esse manejo em suas propriedades diminui para $56 \%$ no ano de 2009 e $52,94 \%$ no ano seguinte, pois $48 \%$ dos produtores em 2009 e 52,94\% em 2010 relataram que não houve incidência de pragas em suas lavouras de sorgo.

Quanto à análise químicobromatológica, $96 \%$ dos produtores em 2009 e 78,44\% em 2010 não realizaram essa prática, devido ao fato de não ter conhecimento dos benefícios que os resultados podem trazer para o sistema produtivo. Nesse sentido, existe um desconhecimento da composição química da silagem de sorgo o que não possibilita a adição de leguminosas como a leucena durante a ensilagem o que melhoraria a composição bromatológica da silagem proporcionando melhores resultados (EVANGELISTA et al., 2005).

$\mathrm{O}$ valor nutritivo da planta forrageira é representado pela associação da composição bromatológica, digestibilidade e consumo voluntário, logo é de grande importância o conhecimento desses fatores na hora do ajuste de dieta. Assim, nota-se a necessidade da criação de programas de extensão rural, onde se tenha a divulgação de técnicas e novas tecnologias, que os produtores possam aplicar em suas propriedades, para aprimorar o sistema produtivo e reduzir custos.

No que diz respeito aos sistemas de cultivo utilizados pelos produtores, em ambos os anos de avaliação, o mais utilizado foi a semeadura direta, aplicada em $78 \%$ das propriedades na primeira avaliação e em $92,16 \%$ no ano seguinte. O plantio direto é uma técnica eficiente no controle das perdas de solo e água, devido ao menor revolvimento do solo, contribuindo para o controle da erosão e aumento da fertilidade do solo, razões que, juntamente com outras vantagens, justificam sua adoção por um número cada vez maior de agricultores (COSTA et al., 2003; SANTOS et al., 2007). Os demais produtores entrevistados utilizaram o sistema de semeadura convencional ou então o de cultivo mínimo.

A adubação nitrogenada apresenta efeito positivo sobre a produtividade da cultura e qualidade da forragem de sorgo (FOLONI et al., 2008). Nesse caso, verificou-se que a maioria dos produtores utilizou adubação nitrogenada em suas lavouras, sendo a forma de ureia a mais utilizada, onde $78 \%$ dos produtores fizeram aplicação da mesma em 2009 e 76,47\% no ano seguinte, com aplicação variando de 80 a $500 \mathrm{~kg}$ por hectare. Para tanto, é necessário que a recomendação da dose de adubo nitrogenado seja de acordo com as deficiências do solo satisfazendo o requerimento da cultura com o mínimo de risco ambiental (AMADO et al., 2002).

Os produtores buscam, cada vez mais, obter aumento na produtividade por área e a redução de custos. Dessa forma, muitas vezes acabam optando por utilizar a mão de obra familiar para realizar certas operações na propriedade. Assim, verificouse que a operação de semeadura, em sua maior parte foi realizada pelos próprios produtores, com representatividade de $50 \%$ no primeiro ano e $80,39 \%$ no segundo ano. Da mesma forma, verifica-se que ocorreu uma redução no espaçamento médio entre 
fileiras de $70 \mathrm{~cm}$ em 2009 para $55 \mathrm{~cm}$ em 2010 (Tabela 1), a fim de se obter maior rendimento por área.

Com relação às culturas utilizadas anteriormente ao sorgo, a mais utilizada nos dois anos de pesquisa foi a aveia (Tabela 4), a qual pode contribuir para a conservação e restauração da estrutura do solo, aumentando a resistência a penetração do solo e a rigidez do sistema (STONE \& SILVEIRA, 2001). Porém, a utilização de aveia como cultura antecessora ao sorgo, pode acabar gerando problemas em relação à disponibilização do nitrogênio pela alta relação $\mathrm{C} / \mathrm{N}$ (HEINRICHS et al., 2001). Nesse caso, sugere-se a rotação de culturas, com espécies capazes de realizar simbiose com microrganismos, fixar nitrogênio, ou então espécies com grande capacidade de reciclar nutrientes (FONSECA et al., 2007).

No que se refere ao processo de ensilagem, apenas $28 \%$ dos produtores em 2009 e $27,45 \%$ em 2010 possuíam ensiladeira própria, fato esse que mais uma vez remete à realidade da agricultura familiar da região, onde se tem pouca infraestrutura e baixo nível tecnológico. Os demais produtores utilizaram ensiladeira de cooperativas, associações com outros produtores, prefeitura, ou então contrataram uma equipe para realizar a ensilagem do sorgo.

Quanto ao modo de estocagem da silagem, todos os produtores entrevistados nos dois anos utilizam silos horizontais, devido as vantagens como baixo custo de construção e facilidades com mão de obra no carregamento e descarregamento, sendo que o tipo trincheira foi o mais utilizado em 2009 , por $72 \%$ dos produtores e o de superfície o mais utilizado em 2010, por $58,82 \%$ dos produtores.

Vieira et al. (2011), verificaram em estudo com a cultura do milho, que o silo tipo trincheira foi o mais utilizado pelos produtores, em 84,26\% das propriedades. Já o tamanho médio dos silos foi de $140,65 \mathrm{~m}^{3}$ em 2009 e 141,42 $\mathrm{m}^{3}$ em 2010, com variações entre 18 e $750 \mathrm{~m}^{3}$.

Tabela 4. Número de produtores de sorgo (NP) e percentual (\%) referente à cultura antecessora ao sorgo utilizado para silagem em propriedades leiteiras no sudoeste do Paraná.

\begin{tabular}{lcccc}
\hline & \multicolumn{2}{c}{$\mathbf{2 0 0 9}$} & $\mathbf{2 0 1 0}$ & $\mathbf{2 0}$ \\
\hline Cultura & NP & $(\boldsymbol{\%})$ & 20 & 40 \\
Trigeia & 24 & 48 & 3 & 6 \\
Azevém & 0 & 0 & 1 & 2 \\
Soja & 4 & 8 & 10 & 20 \\
Sorgo & 7 & 14 & 1 & 2 \\
Feijão & 1 & 0 & 1 & 2 \\
Fumo & 0 & 4 & 0 & 0 \\
Milho & 2 & 20 & 14 & 28 \\
Pastagens & 10 & 4 & 0 & 0 \\
\hline Total & 2 & 100 & 50 & 100 \\
\hline
\end{tabular}


A eficiência dos sistemas de conservação de forragens não deve ser avaliada somente pelo valor nutritivo do produto final, mas também pelas perdas que se tem de silagem. Sendo assim, verificou-se que as maiores perdas de silagem ocorrem no silo, representadas por $54 \%$ dos produtores em 2009 e 82,36\% em 2010. Fato esse que está relacionado diretamente com os processos de ensilagem e descarregamento, ambos ligados ao manejo utilizado pelos produtores, em muitos casos inadequados, por falta de conhecimento e informações técnicas. Os produtores também relataram que ocorreram perdas nos cochos por rejeição dos animais e também no momento da colheita, onde mais uma vez notou-se a falta de orientação técnica aos produtores.

Com relação ao período de utilização da silagem, identificou-se que muitos produtores utilizaram silagem o ano todo, sendo representado por $60 \%$ dos produtores em 2009 e 47,06\% em 2010. A inclusão de silagem na dieta de bovinos leiteiros pode vir a encarecer o processo de produção, se utilizada de forma inadequada, porém permite equilíbrio na produtividade do rebanho, devido a estabilidade que se tem o ano todo na alimentação do rebanho. Os demais produtores entrevistados utilizam a silagem apenas nos períodos onde ocorre escassez de alimento e baixa produtividade das pastagens, o chamado vazio forrageiro. No que diz respeito às correlações entre as características, serão apresentadas e discutidas apenas para aquelas que possuem relação causa e efeito e que possuem uma explicação lógica (Tabela 5).

Ocorreu interação moderada positiva, nos dois anos de estudo (0,67 em 2009 e 0,74 em 2010), entre a área total e o tamanho do silo, ou seja, quanto maior a área da propriedade, maior foi o tamanho do silo utilizado.

Tabela 5. Correlações de Pearson entre as variáveis avaliadas: área total da propriedade (AT), área cultivada com sorgo para silagem (AC), ciclo das cultivares (CC), realização de controle de pragas (CP), tamanho do silo (TS), produção de leite por vaca por dia (PROD), principais pragas incidentes (PGI), local de maiores perdas de silagem (MPS), produção de silagem (PSI), raça dos animais.

\begin{tabular}{|c|c|c|c|c|c|c|c|}
\hline \multicolumn{8}{|c|}{2009} \\
\hline & AT & $\mathrm{AC}$ & $\mathrm{CC}$ & $\mathbf{C P}$ & TS & PROD & PSI \\
\hline PGI & $-0,17$ & 0,14 & 0,12 & $-0,35$ & 0,16 & & $-0,33$ \\
\hline MPS & $-0,05$ & 0,25 & 0,05 & $-0,21$ & 0 & & $-0,13$ \\
\hline TS & 0,67 & 0,27 & $-0,05$ & 0,05 & & & $-0,15$ \\
\hline PROD & $-0,03$ & 0,24 & $-0,27$ & $-0,31$ & $-0,09$ & & \\
\hline PSI & $-0,29$ & 0,04 & 0,16 & $-0,54$ & $-0,15$ & 0,43 & \\
\hline \multicolumn{8}{|c|}{2010} \\
\hline & AT & $\mathrm{AC}$ & $\mathrm{CC}$ & $\mathbf{C P}$ & TS & PROD & PSI \\
\hline PGI & $-0,16$ & $-0,37$ & 0,14 & 0,49 & $-0,22$ & & 0,57 \\
\hline MPS & $-0,15$ & 0,09 & $-0,14$ & $-0,11$ & $-0,21$ & & $-0,51$ \\
\hline TS & 0,74 & 0,56 & $-0,25$ & $-0,19$ & & & 0,12 \\
\hline PROD & 0,20 & 0,27 & $-0,27$ & $-0,20$ & 0,53 & & $-0,09$ \\
\hline PSI & $-0,09$ & $-0,40$ & 0,13 & 0,48 & 0,12 & $-0,09$ & \\
\hline
\end{tabular}


Também foi encontrada interação moderada positiva, no ano de 2010, para a área cultiva com sorgo para silagem e o tamanho do silo $(0,56)$, concluindo-se que quanto maior a área cultivada, maior o tamanho do silo. Da mesma forma, que a interação entre o tamanho do silo e produtividade de leite por vaca/dia foi moderada positiva para o ano de 2010 $(0,53)$, ou seja, à medida que se aumenta o tamanho do silo, se aumenta a produção de leite por animal. Nessa correlação, deve-se considerar que produtores maiores (maiores tamanhos de silos) possuem maiores cuidados técnicos com o rebanho e com isso uma produção mais ajustada para elevar a produtividade por animal.

Para as variáveis produção de silagem e pragas incidentes, a interação também foi moderada positiva no ano de 2010 (0,57), ou seja, à medida que se aumenta a produção de silagem também aumenta a incidência de pragas. Já para as variáveis produção de silagem e local de maiores perdas de silagem, a interação foi moderada negativa no ano de $2010(-0,51)$, ou seja, à medida que aumenta a produção de silagem de sorgo as perdas são reduzidas. Para as demais variáveis não ocorreu interação significativa.

\section{CONCLUSÕES}

Pela avaliação dos questionários aplicados, considera-se fundamental que o trabalho de extensão rural seja incentivado e ampliado, esclarecendo dúvidas e melhorando o manejo das propriedades leiteiras do sudoeste do Paraná.

O desenvolvimento e a produtividade da cultura do sorgo são afetados principalmente, pelas técnicas de manejo adotadas e realizadas pelos produtores.

A técnica do plantio direto está bem instalada na região. Em contrapartida, a maior parte dos agricultores não realiza análises químico - bromatológicas, desconhecendo, portanto, a qualidade das silagens.

O trabalho indica que em todas as etapas do processo de utilização do sorgo existem deficiências na adoção de manejos específicos que garantem ou ampliam a produtividade. Dados técnicos e científicos referentes a este assunto existem na literatura. A dificuldade está localizada na transferência desses resultados ao produtor. Para tanto, se faz necessária a condução de um projeto de extensão, focado na divulgação desses resultados, conscientizando produtores quanto a adoção de técnicas desenvolvidas para a maximização do potencial produtivo da cultura, bem como acompanhamento técnico em todas as etapas do processo

\section{REFERÊNCIAS BIBLIOGRÁFICAS}

AMADO, T.J.C.; MIELNICZUK, J.; AITA, C. 2002. Recomendações de adubação nitrogenada para o milho no RS e SC adaptada ao uso de culturas de cobertura do solo, sob sistema de plantio direto. Revista Brasileira de Ciência do Solo, Viçosa, v. 26, n. 1, p. 241-248.

AMARAL, S.R.; LIRA, M.A.; TABOSA, J.N.; SANTOS, M.V.F.; MELLO, A.C.L.; SANTOS, V.F. 2003. Comportamento de linhagens de sorgo forrageiro submetidas a déficit hídrico sob condição controlada. Pesquisa Agropecuária Brasileira, Brasília, v. 38, n. 8, p. 973-979.

CARRARO, I.M. 2009. Panorama de Produção e Utilização de Sementes no Brasil. Associação Paulista dos Produtores de Sementes e Mudas. Disponível em: <http:// www.apps.agr.br/artigos/?INFOCOD=19 >. Acesso em: 10 de fevereiro de 2011.

COSTA, F.S.; ALBUQUERQUE, J.A.; BAYER, C.; FONTOURA, S.M.V.; 
WOBETO, C. 2003. Propriedades físicas de um latossolo bruno afetadas pelos sistemas plantio direto e preparo convencional. Revista Brasileira de Ciência do Solo, Viçosa, v. 27, n. 3, p. 527-535.

DIAS, A.M.A.; BATISTA, Â.M.V.; FERREIRA, M.A.; LIRA, M.A.; SAMPAIO, I.B.M. 2001. Efeito do estádio vegetativo do sorgo (Sorghum bicolor (L.) Moench) sobre a composição química da silagem, consumo, produção e teor de gordura do leite para vacas em lactação, em comparação à silagem de milho (Zea mays (L.)). Revista Brasileira de Zootecnia, Viçosa, v. 30, n. 6, p. 20862092.

EVANGELISTA, A.R.; ABREU, J.G.; AMARAL, P. N.C. do; PEREIRA, R.C.; SALVADOR, F.M.; LOPES, J.; SOARES, L.Q. 2005. Composição bromatológica de silagem de sorgo (Sorghum bicolor (L.) MOENCH) aditivadas com forragem de leucena (Leucaena leucocephala (LAM.) DEWIT). Ciência e Agrotecnologia, v.29, n.2, p.429-435.

FOLONI, J.S.S.; SANTOS, D.H.; CRESTE, J.E, TOZATTI, H.M. 2008. Desempenho de cultivares de sorgo e milheto submetidos à adubação nitrogenada de cobertura via pulverização foliar. Colloquium Agrariae, Presidente Prudente, v. 4, n. 1, p. 38-47.

FONSECA, G.C.; CARNEIRO, M.A.C.; COSTA, A.R.; OLIVEIRA; G.C.; BALBINO, L.C. 2007. Atributos físicos, químicos e biológicos de latossolo vermelho distrófico de cerrado sob duas rotações de cultura. Pesquisa Agropecuária Tropical, Goiânia, v. 1, n. 37, p. $22-30$.
GUERREIRO, P. K.; MACHADO; M. R. F.; BRAGA， G. C.; GASPARINO, E.; FRANZENER, A. S. M. 2005. Qualidade microbiológica de leite em função de técnicas profiláticas no manejo de produção. Ciência e Agrotecnologia, Lavras, v. 29, n. 1, p. 216-222.

HEINRICHS, R.; AITA, C.; AMADO, T.J.C.; FANCELLI, A.L. Cultivo consorciado de aveia e ervilhaca: relação $\mathrm{C} / \mathrm{N}$ da fitomassa e produtividade do milho em sucessão. Revista Brasileira de Ciência do Solo, v.25, p.331-340, 2001.

IPARDES. 2010. Base de dados do Estado. Disponível em: <www.ipardes.gov.br>. Acesso em: 02 de fevereiro de 2011.

\section{MAARK, R. 1968. Geografia Física do} Estado do Paraná. Curitiba, Banco de desenvolvimento do Paraná, 350p.

MELLO, R.; NÖRNBERG, J. L.; ROCHA, M. G.; DAVID, D. B. 2003. Análise produtiva e qualitativa de um híbrido de sorgo interespecífico submetido a dois cortes. Revista Brasileira de Milho e Sorgo, Sete Lagoas, v. 2, n. 1, p. 20-33.

MOREIRA, A. L.; PEREIRA, O. G.; GARCIA, R.; VALADARES FILHO, S. C.; CAMPOS, J. M. S.; SOUZA, V. G.; ZERVOUDAKIS, J. T. 2001. Produção de leite, consumo e digestibilidade aparente dos nutrientes, $\mathrm{pH} e$ concentração de amônia ruminal em vacas lactantes recebendo rações contendo silagem de milho e fenos de alfafa e de capim-coastcross. Revista Brasileira de Zootecnia, Viçosa, v. 30, n. 3, p. 1089-1098.

NEUMANN, M.; RESTLE, J.; ALVES FILHO, D. C.; BRONDANI, I. L.; PELLEGRINI, L. G.; FREITAS, A. K. 2002. Avaliação do valor nutritivo da planta e da silagem de diferentes híbridos de sorgo (Sorghum bicolor (L.) 
Moench). Revista Brasileira de Zootecnia, Viçosa, v. 31, n. 1, p. 293301.

NEUMANN, M.; RESTLE, J.; BRONDANI, I.L.; NÖRNBERG, J.L.; MELLO, R.O.; SOUZA, A.N.M.; PELLEGRINI, L.G. 2005. Efeito do tamanho da partícula e tipo de silo sobre o valor nutritivo da silagem de sorgo (Sorghum bicolor (L.) Moench). Revista Brasileira de Milho e Sorgo, Sete Lagoas, v. 4, n. 2, p. 224-242.

NEUMANN, M.; RESTLE, J.; NÖRNBERG, J.L.; OLIBONI, R.; PELLEGRIN, L.G.; FARIA, M.V.; OLIVEIRA, M.R. 2008. Efeito associativo do espaçamento entre linhas de plantio, densidade de plantas e idade sobre o desempenho vegetativo e qualitativo do sorgo forrageiro. Revista Brasileira de Milho e Sorgo, Sete Lagoas, v. 7, n. 2, p. 165-181.

OLIVEIRA, J.S.; SOBRINHO, F.S.; FERNANDES, S.B.V.; WÜNSCH, J.A.; LAJÚS, C.A.; DUFLOTH, J.H.; ZANATTA, J.C.; MOLETTA, J.L.; PEREIRA, A.V.; LEDO, F.J.S.; BOTREL, M.A.; AUAD, M.V. 2004. Estratificação de ambientes, adaptabilidade e estabilidade de híbridos comerciais de milho para silagem no sul do Brasil. Ciência Rural, Santa Maria, v. 34 , n. 4 , p. $997-1003$.

PAULA, M.C.; MARTINS, E.N.; SILVA, L. O.C.; OLIVEIRA, C.A.L.; VALOTTO, A.A.; RIBAS, N.P. 2009. Interação genótipo $\mathrm{x}$ ambiente para produção de leite de bovinos da raça Holandesa entre bacias leiteiras no estado do Paraná. Revista Brasileira de Zootecnia, Viçosa, v. 38, n. 3, p. 467-473.

SANTOS, H.P.; TOMM, G.O.; SPERA, S.T.; ÁVILA, A. 2007. Efeito de práticas culturais na conversão e no balanço energéticos. Bragantia, Campinas, v. 66, n. 2, p. 299-306.

SILVA, A.G.; BARROS, A.S.; TEIXEIRA, I.R. 2007. Avaliação agronômica de cultivares de sorgo forrageiro no Sudoeste do Estado de Goiás em 2005. Revista Brasileira de Milho e Sorgo, Sete Lagoas, v. 6, n. 1, p. 116-127.

STONE, L.F.; SILVEIRA, P.M . 2001. Efeitos do sistema de preparo e da rotação de culturas na porosidade e densidade do solo. Revista Brasileira de Ciência do Solo, Viçosa, v. 25, n. 2, p. 395-401.

VANIN, A.; SILVA, A.G.; FERNANDES, C.P.C.; FERREIRA, W.S.; RATTES, J.F. 2011. Tratamento de sementes de sorgo com inseticidas. Revista Brasileira de Sementes, Londrina, v. 33, n. 2, p. 299-309.

VIEIRA, V.C.; MORO, V.; FARINACIO, D.; MARTIN, T.N.; MENEZES, L.F.G. 2011. Caracterização da silagem de milho produzida em propriedades rurais do sudoeste do Paraná. Revista Ceres, Viçosa, v. 58, n. 4, p. 462-469.

Recebido em: 22/05/2013 Aceito para publicação em: 28/11/2013 